Review Article:

\title{
Investigating the Prevalence of Musculoskeletal Pain Among Iranian Children and Adolescents: A Systematic Review and Meta-Analysis
}

\author{
Masoud Hatefi ${ }^{1}$ (D), Alireza Abdi ${ }^{2}$ (D), Asma Tarjoman ${ }^{3}$ (D), Milad Borji2* (D) \\ 1. Department of Neurosurgery, Faculty of Medicine, Medical University of Ilam, Ilam, Iran. \\ 2. Department of Nursing, Faculty of Nursing and Midwifery, Kermanshah University of Medical Sciences, Kermanshah, Iran. \\ 3. Student Research Committee, Kermanshah University of Medical Sciences, Kermanshah, Iran.
}

\begin{tabular}{l|l}
$\begin{array}{l}\text { Use yourdevice to scan } \\
\text { and read the article online }\end{array}$ \\
Adolescents: A Systematic Review and Meta-analysis. Journal of Pediatrics Review. 2019; 7(4):191-198. https://doi.org/10.32598/ \\
jpr.7.4.191
\end{tabular}

\section{(c) (i) (5)}

Article info:

Received: 04 August 2018

First Revision: 24 August 2018

Accepted: 28 January 2019

Published: 01 October 2019

Key Words:

Pain, Musculoskeletal disorders, Systematic review, Meta-analysis

\begin{abstract}
A B S T R A C T
Context: Musculoskeletal pain is very common among students and adolescents.

Objectives: The present systematic review and meta-analysis study aimed to determine the prevalence of musculoskeletal pain among Iranian children and adolescents.

Data Sources, Study Selection, and Data Extraction: All articles on the prevalence of musculoskeletal disorders in Iranian adolescents were searched in the Google Scholar, four Iranian databases and five international English-language databases using the keywords of "pain", "musculoskeletal disorders", "low back pain", "adolescents", "students", and a combination of these keywords. The obtained data were analyzed by Comprehensive MetaAnalysis (CMA) software.

Results: The findings showed that out of 9 studies found in this systematic review and metaanalysis, 6 articles were about low back pain, 6 articles about neck pain, and 3 articles about shoulder pain, respectively. According to the findings, $25.4 \%$ (95\% Cl: 19.0 to 33.0$)$ of the children experienced pain; the prevalence rates of low back pain, knee pain, and the shoulder pain were $26.2 \%$ ( $95 \% \mathrm{Cl}: 14.3$ to 43.0 ), $22 \%$ (95\% Cl: 14.5 to 32.0 ), and $29.3 \%$ (95\% Cl: 20.1 to 40.7) in Iranian adolescents, respectively.
\end{abstract}

Conclusion: Considering the high prevalence of pain among Iranian adolescents, it is necessary to carry out appropriate interventions for pain prevention among this age group. 


\section{Context}

ain is defined as an unpleasant experience that may cause tissue damage (1). Musculoskeletal disorders and discomforts are among the most important causes of pain in students and adolescents (2). Musculoskeletal disorders are also one of the major causes of occupational injury and disability in developing countries and impose high financial and medical costs $(3,4)$.

If pain is not treated in children, it causes problems such as anxiety, lowered pain threshold, reduced effectiveness of palliatives, school absenteeism, reduced physical activity, and limited daily activities (5-8). One of the types of skeletal musculoskeletal disorders is Low Back Pain (LBP), which affects the lower part of the spine and manifests itself in the form of acute and chronic symptoms. This type of pain is one of the most common types of musculoskeletal aches that anyone may experience it $(9,10)$.

The prevalence and cost of LBP, which has been turned into a general problem, shows an increasing trend in societies (11). LBP epidemiology has been studied in adults more widely, but there are few studies on this problem in children (12). Lower back pain in adolescents is likely to be a major cause of back pain in adolescence, so it is vital to take into account the LBP during adolescence (6).

Various factors are associated with LBP in children and adolescents including school issues, physical activity, lifestyle, and psychosocial factors $(13,19)$. All of these factors may affect the LBP incidence rate that influences children's health status (20). So it is necessary to study the incidence of LBP in adolescents.

Various studies have been conducted in Iran through systematic review and meta-analysis of pain outcomes. However, no study deals explicitly with the prevalence of pain in children and adolescents. For example, Azizpour et al. study (21) aimed at determining the prevalence of one year LBP in all age groups, and Mohammadi et al. study (22) assessed the prevalence of LBP in nurses. Therefore, it is necessary to pay attention to the pain in Iranian adolescents and young people.

\section{Objective}

Pain affects the health status of children and adolescents. That is why it is essential to pay attention to it. Identifying the prevalence of pain can help healthcare providers to take the necessary measures to prevent and manage it. Considering that previous studies have focused only on the prevalence of back pain in different cities of Iran and there is no accurate statistics on its overall incidence, the present study aims to determine the prevalence of musculoskeletal pain among Iranian children and adolescents through systematic review and meta-analysis.

\subsection{Study protocol}

The present study is a systematic and meta-analytic review study that investigates the prevalence of musculoskeletal disorders among children and adolescents.

\section{Data Sources and Study Selection}

All articles on the prevalence of musculoskeletal disorders among Iranian adolescents were searched in the Google Scholar, four Iranian databases (ISC, Magiran, IranMedex, SID, Iran Doc), and five English databases (Science Direct, Web of Science, Cochrane, Scopus, Embase, and PubMed) using the keywords of "pain", "musculoskeletal disorders", "back pain, Neck pain", "shoulder pain", "elbow pain", "spine pain", "Pediatrics", "children", "Adolescents", "Students", and/or a combination of these words and expressions. The Boolean operators of "AND" and "OR" were used to combine search results, for example in PubMed (Pain AND/OR Musculoskeletal disorders AND/OR back pain AND/OR neck pain AND/OR shoulder pain AND/OR elbow pain AND spine pain AND/OR Pediatrics AND/OR children AND/OR adolescents AND/OR Iran).

\section{Data Extraction}

The present study research was limited to articles published in foreign and domestic journals up to June 2018, also theses, national and international congresses, and organizational reports. First, all articles that were published on the prevalence of musculoskeletal disorders among Iranian adolescents were collected by the researchers. Then, the unrelated, interventional, and duplicate case reports and studies with incomplete data were excluded. To reduce the bias, the articles were searched independently by two researchers, and in case of any disagreement, that article was evaluated by the third author who is an expert of the systematic and meta-analytic review studies. The flowchart of the study is presented in Figure 1.

\subsection{Quality of studies}

The methodological quality of the articles was evaluated based on the STROBE (The strengthening the reporting 


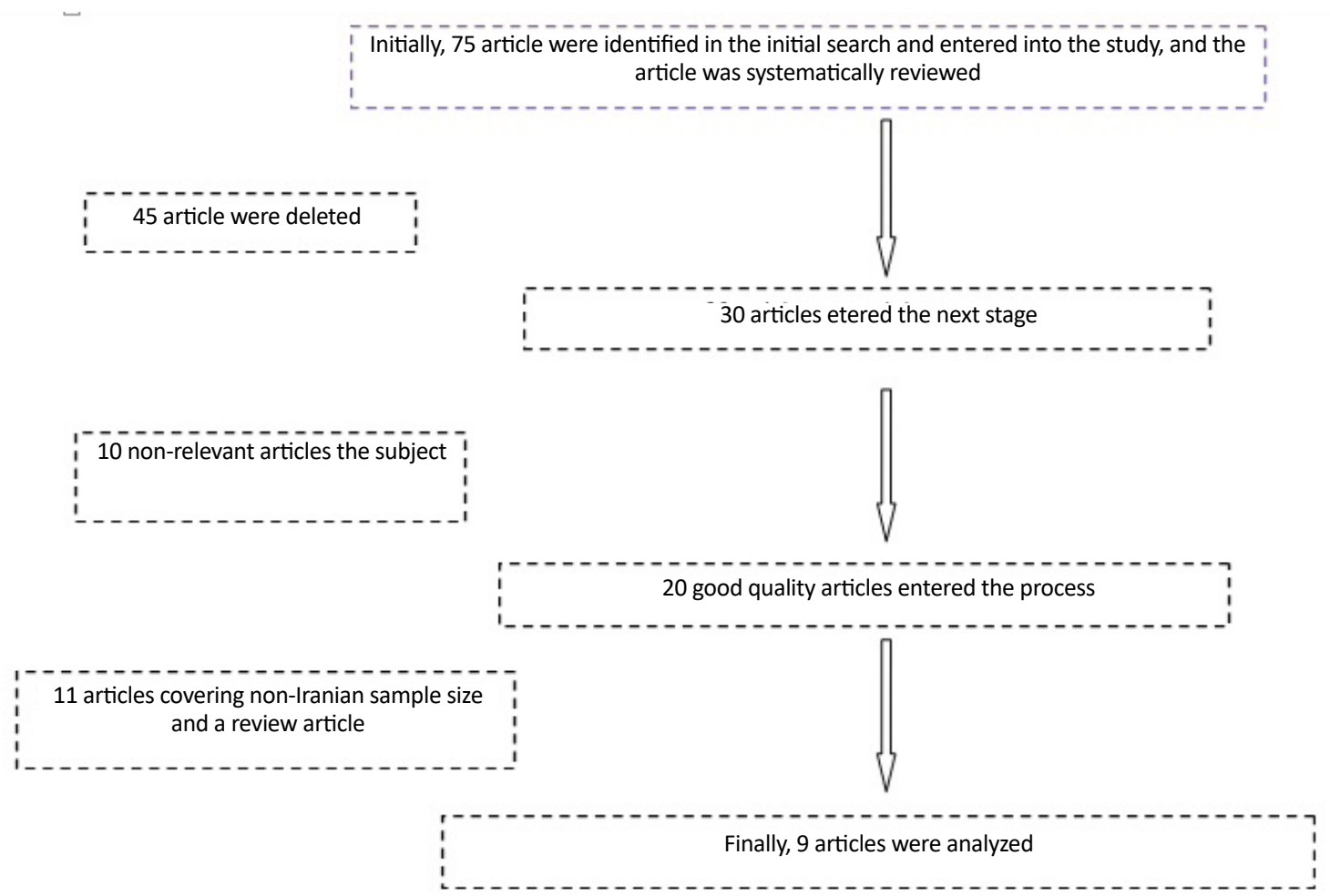

Figure 1. Flowchart for systematic review and meta-analysis

Journal of Pediatrics Review

of observational studies in epidemiology) checklist (23), which consisted of 22 items, including study design, comparison groups, the subjects' characteristics, sample size, and study tools. In this checklist, each item is assigned a score of 0 to 2, with higher scores indicating higher methodological quality. The following specifications related to the research objectives were recorded: article title, name of the first author, the year of publication, city of the study, geographic area of the study, type of questionnaire surveyed, sample size (number of the boys and girls), average age of the subjects, target population, sampling method, and database containing the articles.

\subsection{Data analyses}

The obtained data were analyzed by Comprehensive Meta-Analyses (CMA) software. Heterogeneity was assessed by Cochran's $Q$ test and $I^{2}$. The heterogeneities of the studies were divided into less than $25 \%$ (low heterogeneity), 25-75\% (moderate heterogeneity) and more than $75 \%$ (high heterogeneity). We used subgroup analysis to assess the prevalence of musculoskeletal pain based on the site of pain and location of the studies. The sensitivity analysis of the studies was done to check the robustness of the data.

\section{Results}

Table 1 shows the characteristics of the studies entered into the meta-analysis phase. According to the findings, 9 studies that met the inclusion criteria were entered into the analysis. Of these 9 studies, 6, 6, and 3 studies focused on LBP, neck pain, and shoulder pain, respectively. Figure 2 shows the overall prevalence of pain among Iranian adolescents. Apparently, 25.4\% (95\% Cl: $19.0 \%$ to $33.0 \%$ ) of the Iranian children experience pain. According to Figure 3, the prevalence of LBP, knee pain, and the shoulder pain was $26.2 \%(95 \% \mathrm{Cl}: 14.3 \%$ to $43.0 \%$ ), $22 \%$ (95\% Cl: $14.5 \%$ to $32.0 \%$ ), and $29.3 \%$ (95\% Cl: $20.1 \%$ to $40.7 \%$ ) in Iranian adolescents, respectively. Figure 4 shows the prevalence of musculoskeletal pain based on the location of the studies, in which the northeast has the highest prevalence (39\%).

The Kendall's tau in Begg and Mazumdar test showed no publication bias $(z=1.77, P=0.07)$. And Figure 5 shows the funnel plot of the studies. Figure 6 shows the sensitive analysis of the studies indicating no difference with the main results. The quality assessment of the articles indicates that the entered studies into the meta-analysis had the necessary criteria. 
Table 1. Specifications of studies entered into the meta-analysis

\begin{tabular}{|c|c|c|c|c|c|c|c|}
\hline Author & Place & $\begin{array}{c}\text { Geographical } \\
\text { Location }\end{array}$ & $\begin{array}{c}\text { Population } \\
\text { Studied }\end{array}$ & Mean $\pm S D$ & $\mathbf{N}$ & Pain Area & Prevalence \\
\hline \multirow{2}{*}{$\begin{array}{l}\text { Ilbeigi } \\
(14)\end{array}$} & \multirow[t]{2}{*}{ Birjand } & \multirow[t]{2}{*}{ North-east } & \multirow{2}{*}{$\begin{array}{l}\text { Elementary male } \\
\text { students }\end{array}$} & - & \multirow[t]{2}{*}{60} & Back & 40 \\
\hline & & & & & & Neck & 38.33 \\
\hline Jafari (2) & Babol & North & - & $15.96 \pm 1.13$ & 998 & Neck & 34.3 \\
\hline Bayat (35) & Hormozgan & South & $\begin{array}{l}\text { Children and } \\
\text { teenagers }\end{array}$ & $13.1 \pm 0.85$ & 1648 & Back & 48 \\
\hline \multirow{3}{*}{ Shamsedini (36) } & \multirow{3}{*}{ Tehran } & \multirow{3}{*}{ Center } & \multirow{3}{*}{$\begin{array}{l}\text { Elementary and } \\
\text { guidance students }\end{array}$} & \multirow{3}{*}{$13.4(-)$} & \multirow{3}{*}{340} & Shoulders & 18.46 \\
\hline & & & & & & Neck & 13.42 \\
\hline & & & & & & Back & 17.4 \\
\hline $\begin{array}{l}\text { Mohseni-Band- } \\
\text { pay (35) }\end{array}$ & Mazandaran & North & $\begin{array}{l}\text { Students aged } 11 \\
\text { to } 14 \text { years old }\end{array}$ & $13.1 \pm 0.85$ & 4813 & Back & 14.4 \\
\hline \multirow{4}{*}{ Poornajaf (36) } & \multirow{4}{*}{ Ilam } & \multirow{4}{*}{ The west } & \multirow{4}{*}{$\begin{array}{c}\text { Elementary } \\
\text { schools for girls }\end{array}$} & \multirow{4}{*}{ - } & \multirow{4}{*}{244} & Back & 5.3 \\
\hline & & & & & & Neck & 4.5 \\
\hline & & & & & & Elbow & 0.8 \\
\hline & & & & & & Dropping shoulder & 50 \\
\hline \multirow{3}{*}{ Dianat (37) } & \multirow{3}{*}{ Tabriz } & \multirow{3}{*}{ North-west } & \multirow{3}{*}{$\begin{array}{l}\text { Schoolchildren } \\
\text { aged } 12-14 \text { years }\end{array}$} & \multirow{3}{*}{$12.8 \pm 1.27$} & \multirow{3}{*}{586} & Neck & 35.3 \\
\hline & & & & & & Shoulder & 26.1 \\
\hline & & & & & & Low back & 33 \\
\hline
\end{tabular}

Journal of Pediatrics Review

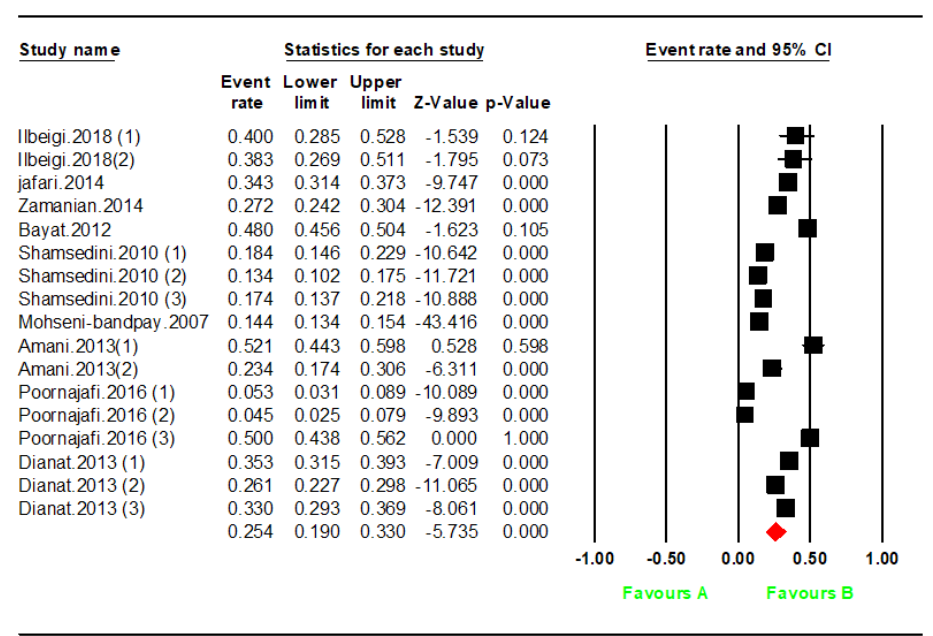

Meta Analysis

Figure 2. The prevalence of musculoskeletal pain in students in Iran

Journal of Pediatrics Review 


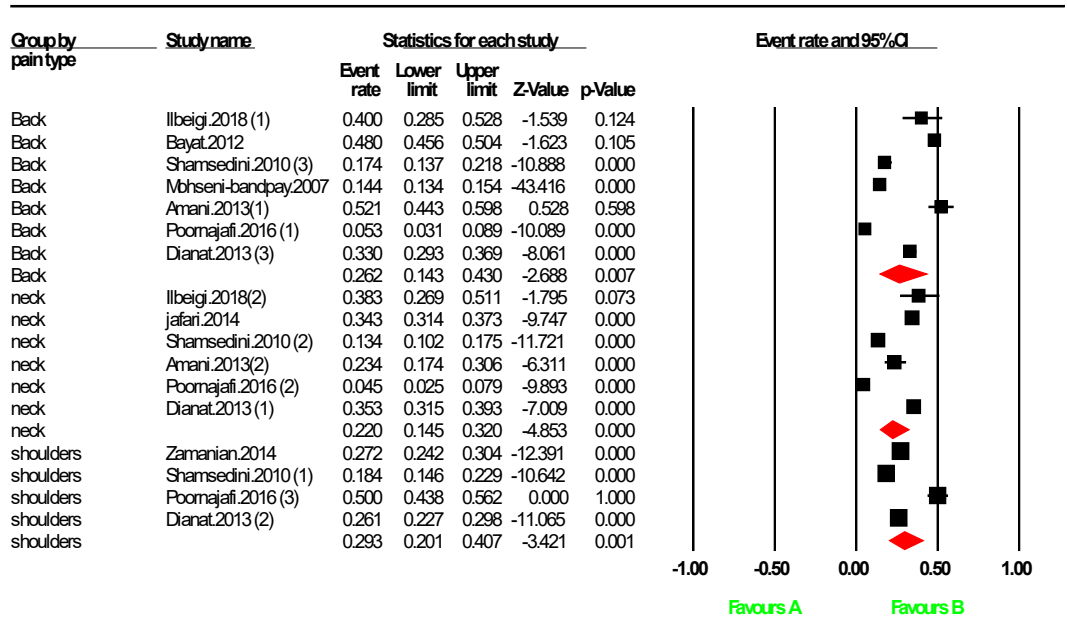

Meta Analysis

Figure 3. The prevalence of musculoskeletal pain based on the site of pain (neck, shoulders, back)

Journal of Pediatrics Review

\section{Discussion}

Pain is one of the most critical issues affecting children's health status in such a way that there is a significant relationship between the amount of pain and quality of life in adolescents. It is, in turn, a cause of concern among adolescent or even adult population $(24,25)$. Therefore, this study was conducted as the first systematic review and meta-analysis on the prevalence of musculoskeletal pain among Iranian adolescents.

The findings of the present study showed that the prevalence of musculoskeletal pain among Iranian children is $25.4 \%$. Algarni et al. reported a prevalence rate of $85.3 \%$ among medical students at University Hospitals at any time (26), which is higher than the results of the present study. The findings of the present study showed that the prevalence of LBP in adolescents was $26.2 \%$, which was higher than the results of Louw et al. systematic review in Africa (12\%) (27). However, these results are consistent with the results of King et al. review study, which was conducted to determine the prevalence of pain in children and adolescents and reported a prevalence rate of $14 \%$ to $24 \%$ (28). LBP is one of the significant problems of adolescents and should be prevented (29). Steffens et al. showed in their review study that exercise could prevent LBP, but back belts and shoe insoles did not affect LBP reduction (30).

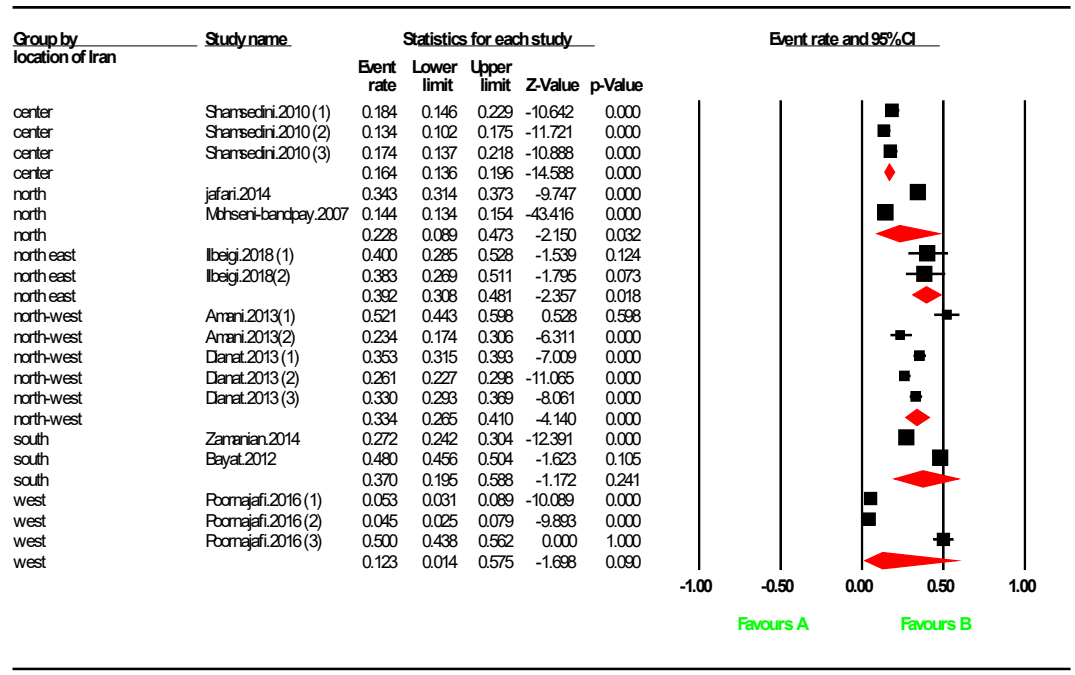

Meta Analysis

Figure 4. The prevalence of musculoskeletal pain based on study location in Iran

Journal of Pediatrics Review 


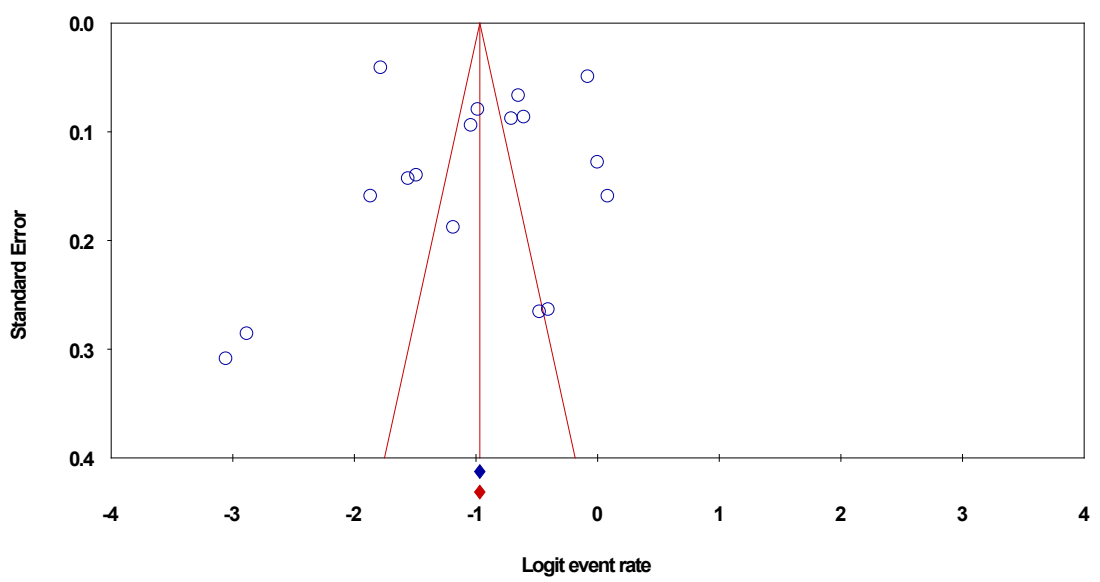

Figure 5: Funnel plot for publication bias

Journal of Pediatrics Review

According to the findings of the present study, the incidence of neck pain in the subjects was $22 \%$. Hoy et al. carried out a review study to determine the burden of pain in patients with neck pain and their findings showed that the global prevalence of neck pain was $4.9 \%$ and this type of pain would cause disability in patients (31). The reported pain in the present study was higher than that of Hoy et al., which might be because the present study was carried out only on Iranian adolescents, while Hoy's study is a global study with its special inclusion criteria (31). Kanchanomai et al. carried out a study on the incidence of neck pain, and their findings showed that $33 \%$ of the subjects experienced persistent neck pain (32), which was more than the results of the present study.

The findings of this systematic review and meta-analysis indicated that $29.3 \%$ of Iranian adolescents had shoulder pain. Alshagga et al. in a study on medical students in Malaysia reported that the shoulder pain was prevalent among $8.6 \%$ and $22.8 \%$ of them during the last week and the previous month, respectively, which was lower than the results of the present study (33). Auvinen et al. reported that half of the girls and onethird of the boys experienced pain in the shoulders, occipital, or neck regions (34), which was consistent with the results of the present study.

The results of this study can provide various information to researchers. Also, it can provide useful information to the general public. Besides, the information on the prevalence of pain in the health care sector can provide helpful insight for managing anxiety, which will provide the necessary grounds for taking preventive measures. About future studies, it is suggested that interventions are needed to reduce the pain of children.

One limitation of this study was that no study had investigated all of the variables. Also, in some studies, complete information is not provided.

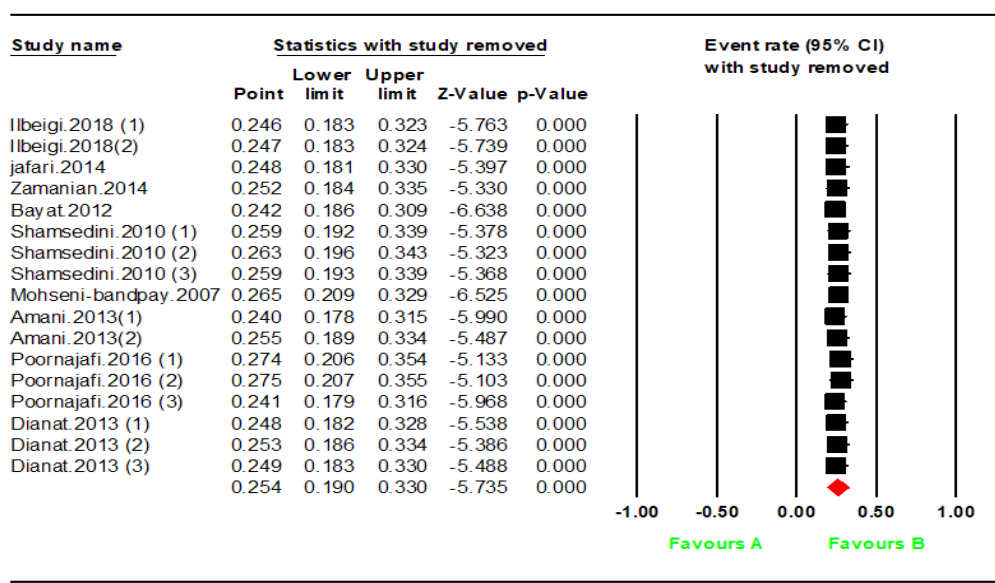

Meta Analysis 


\section{Conclusion}

Considering the high prevalence of pain among Iranian adolescents, it is necessary to design appropriate interventions for pain prevention in this age group.

\section{Ethical Considerations}

\section{Compliance with ethical guidelines}

All ethical principles were considered in this article. The participants were informed about the purpose of the research and its implementation stages; they were also assured about the confidentiality of their information; moreover, they were allowed to leave the study whenever they wish, and if desired, the results of the research would be available to them. (Ethical Code: IR. KUMS. REC. 1397. 838).

Funding

Student Research Committee, Kermanshah University of Medical Sciences has financialy supported this paper (Project Code: 3006964).

\section{Authors' contributions}

All authors contributed in designing, running, and writing all parts of the research.

\section{Conflicts of interest}

The authors declared no conflict of interest.

\section{Reference}

1. Merskey H. Pain terms: A list with definitions and notes on usage. Recommended by the IASP Subcommittee on Taxonomy. Pain. 1979; 6:249-52. [PMID]

2. Ja'fari M, Faraji M, Tirgar A, Bijani A, Javanshir K. [The relationship between school bag characteristics and personal variables with neck pain among high school students of Babol, Iran (Persian)]. Archives of Rehabilitation. 2014; 15(2):4-11.

3. Choobineh A, Rajaeefard A, Neghab M. [Perceived demands and musculoskeletal disorders among hospital nurses (Persian)]. Hakim Research Journal. 2007; 10(2):70-5.

4. Dadarkhah A, Azema K, Abedi M. [Prevalence of musculoskeletal pains among nursing staff in AJA Hospitals-Tehran (Persian)]. Ebnesina. 2013; 15(3):10-7.
5. Taddio A, Chambers CT, Halperin SA, Ipp M, Lockett $D$, Rieder $\mathrm{MJ}$, et al. Inadequate pain management during routine childhood immunizations: The nerve of it. Clinical Therapeutics. 2009; 31:S152-S67. [DOI:10.1016/j. clinthera.2009.07.022] [PMID]

6. Watson KD, Papageorgiou AC, Jones GT, Taylor S, Symmons DP, Silman AJ, et al. Low back pain in schoolchildren: Occurrence and characteristics. Pain. 2002; 97(1-2):87-92. [DOI:10.1016/S0304-3959(02)00008-8]

7. Skoffer B. Low back pain in 15-to 16-year-old children in relation to school furniture and carrying of the school bag. Spine. 2007; 32(24):E713-E7. [DOI:10.1097/ BRS.0b013e31815a5a44] [PMID]

8. Bejia I, Abid N, Salem KB, Letaief M, Younes M, Touzi M, et al. Low back pain in a cohort of 622 Tunisian schoolchildren and adolescents: An epidemiological study. European Spine Journal. 2005; 14(4):331-6. [DOI:10.1007/s00586004-0785-2] [PMID] [PMCID]

9. Lewis S, Holmes P, Woby S, Hindle J, Fowler N. The relationships between measures of stature recovery, muscle activity and psychological factors in patients with chronic low back pain. Manual Therapy. 2012; 17(1):27-33. [DOI:10.1016/j.math.2011.08.001] [PMID]

10. Gerhart JI, Burns JW, Bruehl S, Smith DA, Post KM, Porter LS, et al. Variability in negative emotions among individuals with chronic low back pain: Relationships with pain and function. Pain. 2018; 159(2):342-50. [DOI:10.1097/j. pain.0000000000001102] [PMID]

11. Eldabe SS, Taylor RS, Goossens S, Bouche B, Gültuna I, Green $\mathrm{C}$, et al. A Randomized controlled trial of subcutaneous nerve stimulation for back pain due to failed back surgery syndrome: The subqstim study. Neuromodulation. 2018. [DOI:10.1111/ner.12784] [PMID]

12. Jeffries LJ, Milanese SF, Grimmer-Somers KA. Epidemiology of adolescent spinal pain: A systematic overview of the research literature. Spine. 2007; 32(23):2630-7. [DOI:10.1097/BRS.0b013e318158d70b] [PMID]

13. Kaspiris A, Grivas TB, Zafiropoulou C, Vasiliadis E, Tsadira O. Nonspecific low back pain during childhood: A retrospective epidemiological study of risk factors. Journal of Clinical Rheumatology. 2010; 16(2):55-60. [DOI:10.1097/ RHU.0b013e3181cf3527] [PMID]

14. Ilbeigi S, Kabootari A, Afzalpour M, Farzaneh $\mathrm{H}$. The relationship between sitting posture and musculoskeletal pain in boy elementary school students. Journal of Ergonomics. 2018; 5(3):41-9. [DOI:10.30699/jergon.5.3.41]

15. Feldman DE, Shrier I, Rossignol M, Abenhaim L. Risk factors for the development of low back pain in adolescence. American Journal of Epidemiology. 2001; 154(1):30-6 [DOI:10.1093/aje/154.1.30] [PMID]

16. Sato T, Ito T, Hirano T, Morita O, Kikuchi R, Endo N, et al. Low back pain in childhood and adolescence: Assessment of 
sports activities. European Spine Journal. 2011; 20(1):94-9. [DOI:10.1007/s00586-010-1485-8] [PMID] [PMCID]

17. Wedderkopp N, Kjær P, Hestbaek L, Korsholm L, LeboeufYde C. High-level physical activity in childhood seems to protect against low back pain in early adolescence. The Spine Journal. 2009; 9(2):134-41. [DOI:10.1016/j. spinee.2008.02.003] [PMID]

18. Watson KD, Papageorgiou A, Jones GT, Taylor S, Symmons $D$, Silman A, et al. Low back pain in schoolchildren: The role of mechanical and psychosocial factors. Archives of Disease in Childhood. 2003; 88(1):12-7. [DOI:10.1136/adc.88.1.12] [PMID] [PMCID]

19. Jones GT, Watson KD, Silman AJ, Symmons DP, Macfarlane GJ. Predictors of low back pain in British schoolchildren: A population-based prospective cohort study. Pediatrics. 2003; 111(4):822-8. [DOI:10.1542/peds.111.4.822] [PMID]

20. Kahsay H. Assessment and treatment of pain in pediatric patients. New York: Scholars' Press; 2017.

21. Hemmati F. [Prevalence of one-year back pain in Iran: A systematic review and meta-analysis (Persian)]. Iran Occupational Health. 2014; 11(1):1-2.

22. Mohammadi M, Raiegani AA, Jalali R, Ghobadi A, Salari N. The prevalence of low back pain among Iranian hospital nurses: A systematic review and meta-analysis. Nursing and Midwifery Studies. 2019; 8(1):1-6. [DOI:10.4103/nms. nms_46_18]

23. Von Elm E, Altman DG, Egger M, Pocock SJ, Gøtzsche PC, Vandenbroucke JP, et al. The Strengthening the Reporting of Observational Studies in Epidemiology (STROBE) statement: Guidelines for reporting observational studies. PLOS Medicine. 2007; 4(10):e296. [DOI:10.1371/journal. pmed.0040296] [PMID] [PMCID]

24. Gustafsson M-L, Laaksonen C, Aromaa M, Löyttyniemi E, Salanterä $S$. The prevalence of neck-shoulder pain, back pain and psychological symptoms in association with daytime sleepiness-a prospective follow-up study of school children aged 10 to 15 . Scandinavian Journal of Pain. 2018; 18(3):389-97. [DOI:10.1515/sjpain-2017-0166] [PMID]

25. Gonçalves TR, Mediano MFF, Sichieri R, Cunha DB. Is health-related quality of life decreased in adolescents with back pain? Spine. 2018; 43(14):E822-E9. [DOI:10.1097/ BRS.0000000000002520] [PMID]

26. Algarni AD, Al-Saran Y, Al-Moawi A, Bin Dous A, Al-Ahaideb A, Kachanathu SJ. The prevalence of and factors associated with neck, shoulder, and low-back pains among medical students at university hospitals in central saudi arabia. Pain Research and Treatment. 2017; 2017(1235706):1-7. [DOI:10.1155/2017/1235706] [PMID] [PMCID]

27. Louw QA, Morris LD, Grimmer-Somers K. The prevalence of low back pain in Africa: A systematic review. BMC Musculoskeletal Disorders. 2007; 8:105. [DOI:10.1186/1471-24748-105] [PMID] [PMCID]
28. King S, Chambers CT, Huguet A, MacNevin RC, McGrath PJ, Parker $L$, et al. The epidemiology of chronic pain in children and adolescents revisited: A systematic review. Pain 2011; 152(12):2729-38. [DOI:10.1016/j.pain.2011.07.016] [PMID]

29. Houghton KM. Review for the generalist: Evaluation of low back pain in children and adolescents. Pediatric Rheumatology. 2010; 8:28. [DOI:10.1186/1546-0096-8-28] [PMID] [PMCID]

30. Steffens D, Maher CG, Pereira LS, Stevens ML, Oliveira VC, Chapple $M$, et al. Prevention of low back pain: A systematic review and meta-analysis. The Journal of the American Medical Association. 2016; 176(2):199-208. [DOI:10.1001/ jamainternmed.2015.7431] [PMID]

31. Hoy D, March L, Brooks P, Blyth F, Woolf A, Bain C, et al. The global burden of low back pain: Estimates from the global burden of disease 2010 study. Annals of the Rheumatic Diseases. 2014; 73(6):968-74. [DOI:10.1136/annrheumdis-2013-204428] [PMID]

32. Kanchanomai $S$, Janwantanakul $P$, Pensri $P$, Jiamjarasrangsi $W$. Risk factors for the onset and persistence of neck pain in undergraduate students: 1-year prospective cohort study. BMC Public Health. 2011; 11:566. [DOI:10.1186/1471 2458-11-566] [PMID] [PMCID]

33. Alshagga MA, Nimer AR, Yan LP, Ibrahim IAA, Al-Ghamdi SS, Al-Dubai SAR. Prevalence and factors associated with neck, shoulder and low back pains among medical students in a Malaysian medical college. BMC Research Notes. 2013; 6:244. [DOI:10.1186/1756-0500-6-244] [PMID] [PMCID]

34. Auvinen J, Tammelin T, Taimela S, Zitting P, Karppinen J. Neck and shoulder pains in relation to physical activity and sedentary activities in adolescence. Spine. 2007 32(9):1038-44. [DOI:10.1097/01.brs.0000261349.94823. c1] [PMID]

35. Mohseni-Bandpei MA, Bagheri-Nesami M, ShayestehAzar M. Nonspecific low back pain in 5000 Iranian schoolage children. Journal of Pediatric Orthopaedics. 2007; 27(2):126-9. [DOI:10.1097/BPO.0b013e3180317a35] [PMID]

36. Poornajaf A, Omidi L, Khodadadi I, Rahim NN, Rahmani A, Akbarzadeh $A$, et al. [Backpack and related health problems among school students (Persian)]. Payesh. 2016; 15(1):79-85

37. Dianat I, Sorkhi N, Pourhossein A, Alipour A, Asghari-Jafarabadi $\mathrm{M}$. Neck, shoulder and low back pain in secondary schoolchildren in relation to schoolbag carriage: Should the recommended weight limits be gender-specific? Applied Ergonomics. 2014; 45(3):437-42. [DOI:10.1016/j apergo.2013.06.003] [PMID] 